\title{
Editorial
}

\section{La Revista Biomédica: fin e inicio de un ciclo editorial.}

El presente número de la Revista Biomédica, publicación científica del Centro de Investigaciones Regionales "Dr. Hideyo Noguchi” y de la Facultad de Medicina de la Universidad Autónoma de Yucatán, representa el número 65 desde su inicio en 1990 ( $\sin$ considerar los suplementos publicados) y cursa ya el décimo séptimo año de su edición. Durante estos diecisiete años como publicación científica, ha proporcionado y conservado un registro permanente de las contribuciones que se han publicado y con ello ha contribuido a la difusión del quehacer científico de la Universidad Autónoma de Yucatán, de los investigadores mexicanos y de los profesionales de la actividad científica biomédica de Latinoamérica y de otros países del orbe. Así mismo, la Revista Biomédica ha sido un medio eficiente de comunicación entre investigadores latinoamericanos y de otros países y ha fortalecido la identidad de grupos profesionales dedicados a la investigación científica.

Durante estos años de su publicación, quien esto escribe ha participado en su proceso editorial, cuatro como editor asociado (co-editor) $\mathrm{y}$ trece como editor. Al cumplir treinta años de trabajo en el seno de la Universidad Autónoma de Yucatán, se me ha concedido la jubilación y con ella la separación del cargo de Editor de la Revista Biomédica, responsabilidad que con orgullo y entusiasmo desarrollé. Con esto se cierra un ciclo editorial de la misma y se inicia uno nuevo bajo la batuta del nuevo editor. El carácter institucional y la difusión internacional de la Revista Biomédica (catalogada ya como una revista científica de la biomedicina en Latinoamérica), son las garantías de su continuidad, con una evolución positiva (1-
5), que siempre se ha traducido en mantener la calidad de su contenido, que la define como una publicación científica competitiva en el mundo de la comunicación científica.

Mi agradecimiento sincero a mis Editores Asociados, M.C. Carlos Castro-Sansores e Ing. Bioméd. Fernando J. Álvarez-Cervera, al Administrador Editorial Luis G. Escobedo y Ruiz, a la Lic. Gabriela Solís-Magaña, responsable de la versión electrónica, al Comité Editorial, a los revisores anónimos y a las autoridades universitarias, que durante trece años y en su turno, me otorgaron la confianza y el alto honor de ser el Editor de la Revista Biomédica.

Renán A. Góngora-Biachi.

Editor (1993-2006)

Revista Biomédica, Universidad Autónoma de Yucatán, Mérida, Yucatán, México.

\section{REFERENCIAS.}

1.- Góngora-Biachi RA. Análisis de la Revista Biomédica. Rev Biomed 1995; 6:1-4.

2.- Góngora-Biachi RA. La Revista Biomédica: una década de su publicación. Rev Biomed 1999; 10:197-8.

3.- Álvarez-Cervera FJ, Góngora-Alfaro JL, Bata-García JL, Heredia-López FJ. Análisis de la Revista Biomédica en sus primeros diez años. Rev Biomed 2000; 11:235-49.

4.- Góngora-Biachi RA. Modificaciones a la política editorial de la Revista Biomédica. Rev Biomed 2003; 14:1-2.

5.- Góngora-Biachi RA. La Revista Biomédica: quince años de divulgación científica. Rev Biomed 2004; 15:1-2. 